\title{
Large ductus arteriosus and intact ventricular septum associated with congenital absence of the pulmonary valve
}

\author{
BASIL D THANOPOULOS, ELIZABETH A FISHER, ALOIS R HASTREITER \\ From the Section of Pediatric Cardiology, University of Illinois Medical Center, Chicago, Illinois, USA
}

SUMMARY Clinical, haemodynamic, angiocardiographic, and necropsy findings are reported in a newborn infant who presented with typical findings of the severe form of the syndrome of absent pulmonary valve. In addition to the usual findings of aneurysmal dilatation of the pulmonary arteries, pulmonary insufficiency, and stenosis, this patient had an intact ventricular septum and large ductus arteriosus. The former is a rare finding and the latter is not known to have been reported in a patient with the severe form of this syndrome.

The syndrome of congenital absence of the pulmonary valve is a relatively rare but well described cardiac anomaly. ${ }^{1-3}$ The severe form of this syndrome, characterised by pronounced respiratory distress presenting soon after birth, has been attributed to tracheobronchial compression caused by aneurysmally dilated pulmonary arteries. ${ }^{3}$ The vast majority of reported cases with the severe form of the syndrome had an associated ventricular septal defect and pulmonary stenosis, usually at the level of pulmonary annulus. ${ }^{1-3}$ Absence of the ductus arteriosus, found in a relatively large number of these patients, has been implicated as an important factor contributing to the prenatal development of pronounced dilatation of the pulmonary arteries. ${ }^{3}$

We present this rare case of congenital absence of the pulmonary valve in which there was pulmonary arterial dilatation, a ductus arteriosus, and an intact ventricular septum.

\section{Case report}

This four hour old female presented with tachypnoea, cyanosis, and severe respiratory distress immediately after birth. The peripheral pulses were normal. The lungs were clear. There was a hyperactive precordium with diffuse left parasternal impulse. Systolic and diastolic thrills were palpable

Requests for reprints to Dr Basil D Thanopoulos, Haemodynamic Laboratory, Nikea General Hospital, Phanarioton 3, Nikea 184 54, Piraeus, Greece. at the left upper sternal border. The second heart sound was loud and single. Grade 5/6 systolic and diastolic murmurs with to and fro quality were best heard at the left upper sternal border. The liver was palpable $2 \mathrm{~cm}$ below the right costal margin. The electrocardiogram was normal for age. The chest $x$ ray showed cardiomegaly. The pulmonary arteries were obscured by a large cardiothymic shadow. Because of poor response to medical treatment, cardiac catheterisation was performed at 18 hours of age. A bidirectional shunt was demonstrated at the level of the ductus. Right ventricular systolic pressure $(97 / 11 \mathrm{~mm} \mathrm{Hg})$ was greater than systemic systolic pressure $(70 / 45 \mathrm{~mm} \mathrm{Hg})$, and a $30 \mathrm{~mm} \mathrm{Hg}$ peak systolic pressure gradient was found at the level of the pulmonary annulus.

Cineangiocardiography showed aneurysmal dilatation of the main pulmonary artery and its primary branches (Fig. 1a), and narrowing of the pulmonary annulus. The ventricular septum was intact. Aortography showed a large ductus arteriosus and severe pulmonary insufficiency (Fig. 1b).

The infant died during operation to relieve the right ventricular obstruction and to close the ductus arteriosus.

Necropsy confirmed the above findings. At the level of the narrow pulmonary annulus there were thick nodules of dysplastic fibrous tissue. A ridge extended from the parietal band across the base of the pulmonary ring; this presumably led to further narrowing of the pulmonary orifice (Fig 2 ). 

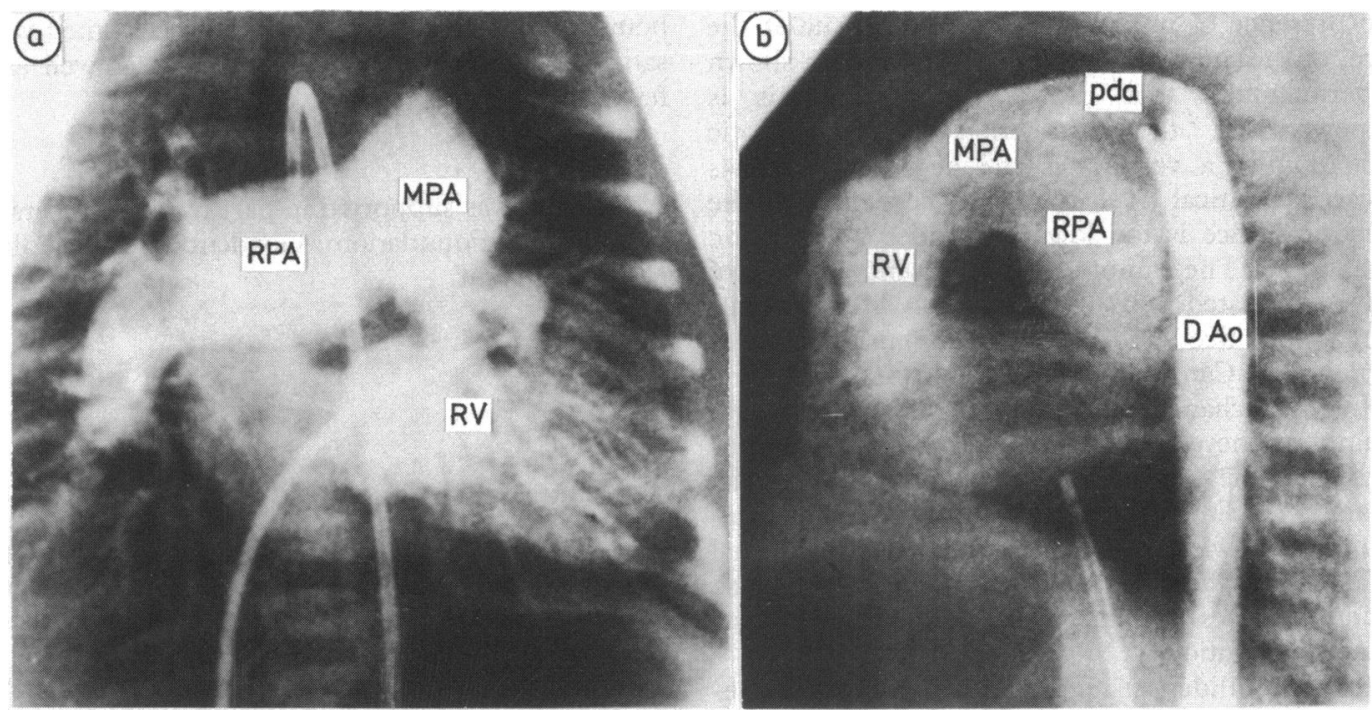

Fig. 1 Selective right ventricular ( $R V$ in (a)) and descending aortic ( $D A$ in in (b)) injections showing massive dilatation of the main pulmonary artery (MPA) and its right (RPA) and left branches in (a) and the large ductus arteriosus (pda) in (b). The right ventricle $(R V)$ is opacified in (b) due to massive pulmonary insufficiency.

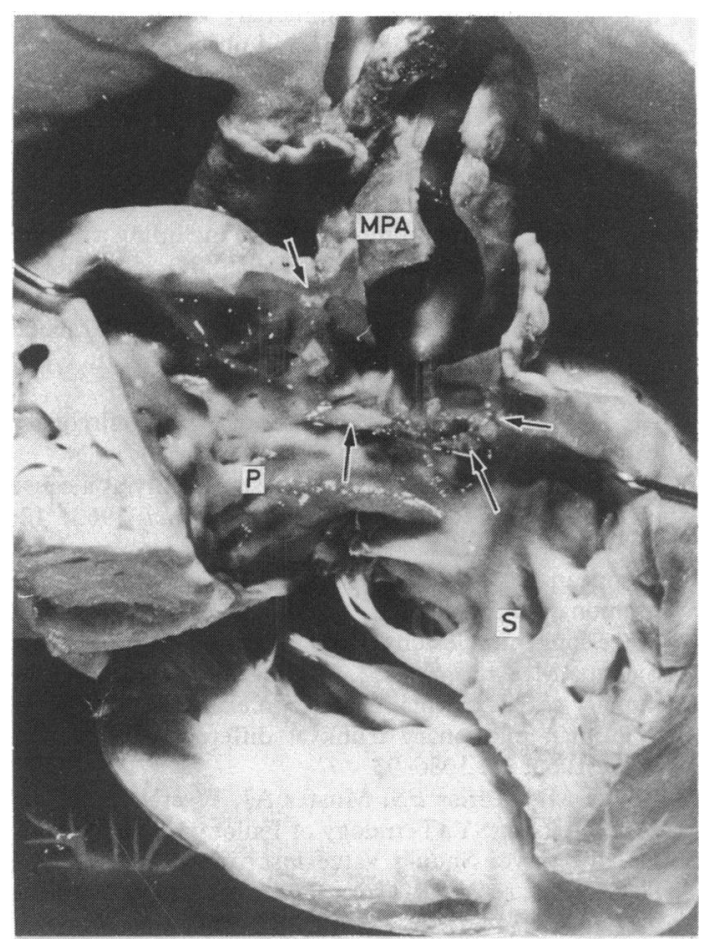

Fig. 2 Right ventricular morphology at necropsy. The narrow pulmonary annulus and valve remnants are shown (arrows). The middle arrow indicates in addition the abnormal ridge which extends from the parietal band $(P)$ to the base of the annulus. $S$, septal band, MPA, main pulmonary artery.

\section{Discussion}

Chevers was the first to describe this complex cardiac lesion. ${ }^{4}$ Since his original report, nearly 170 cases have been reported. Most of the patients had a ventricular septal defect and a stenotic pulmonary annulus. ${ }^{3}$ Infundibular stenosis has been found in some cases. ${ }^{3}$ Congenital absence of the pulmonary valve with intact ventricular septum is extremely rare and has been found as an isolated anomaly, ${ }^{56}$ in association with atrial septal defect, ${ }^{7}$ or in Marfan's syndrome. $^{8}$

Small and irregular beads of primitive connective tissue at the level of the pulmonary annulus or complete absence of valvar tissue plus pronounced dilatation of the pulmonary arteries are the most characteristic findings at necropsy. ${ }^{23}$ In addition, a narrow pulmonary annulus and a ventricular septal defect are common findings. ${ }^{23}$

Atelectasis and obstructive emphysema, secondary to tracheobronchial compression from the aneurysmally enlarged pulmonary arteries, lead to severe respiratory distress in many cases. Many infants die of these severe pulmonary problems soon after birth. ${ }^{3}$

The aneurysmal dilatation of the pulmonary arteries has been attributed to several factors. The haemodynamic effect of increased right ventricular stroke volume due to severe pulmonary insufficiency and poststenotic dilatation secondary to pulmonary stenosis have been felt to be of major importance. ${ }^{13}$ The severity of pulmonary stenosis, usually due to a small pulmonary annulus, may be exaggerated by 
the presence of immobile nodules of tissue at the level of the pulmonary annulus. It has been shown experimentally that the degree of stenosis is important in the production of poststenotic dilatation of a vessel. ${ }^{9}$ If the degree of stenosis exceeds a critical level, the blood flow through the stenotic orifice is too low to produce poststenotic dilatation. ${ }^{9}$ The unique case of absent pulmonary valve associated with a considerably stenotic pulmonary orifice and small pulmonary arteries reported by Campeau et al ${ }^{10}$ supports this theory.

Intrinsic changes of the pulmonary arterial wall, mainly of the elastic tissue, have been also implicated in the production of pulmonary arterial dilatation. ${ }^{8}$ Similar changes of the pulmonary arterial wall, however, have been reported in normal infants up to three years of age ${ }^{11}$ and have been also found in cases of experimentally produced poststenotic dilatation. ${ }^{9}$

Emmanouilides et al found an increased frequency of absent ductus arteriosus in this syndrome. ${ }^{3}$ They postulated that in these cases absence of the ductus arteriosus in fetal life prevents run-off of the increased right ventricular stroke volume into the systemic circuit, and in the presence of the high resistance of the fetal lung, results in the pronounced dilatation of the pulmonary arteries found at birth. Reports that patients with isolated absence of the pulmonary valve had a ductus arteriosus and did not have aneurysmal dilatation of the pulmonary arteries support this theory. The unique findings of pulmonary artery dilatation with a large ductus arteriosus in our case suggest that the absence of the ductus is not critical in the pathogenesis of pulmonary artery dilatation. The single common factor in cases with pulmonary artery dilatation appears to be a narrow pulmonary orifice. We postulate that pulmonary stenosis at the level of the pulmonary annulus in association with increased right ventricular stroke volume is fundamental for the genesis of aneurysmal dilatation of the pulmonary arteries, which is the hallmark of the severe form of this syndrome. It was the absence of pulmonary stenosis and not the presence of a ductus arteriosus which prevented the development of aneurysmal pulmonary artery dilatation in the cases of isolated absence of pulmonary valve mentioned before.

The major symptoms of the severe form of the syndrome are caused by pulmonary artery dilatation. Operation should therefore aim at correction of the pulmonary stenosis and insufficiency in order to prevent further dilatation of the pulmonary arteries. Such surgery, using an aortic valve homograft or heterograft, has been performed with satisfactory results in older patients ${ }^{12}$ as well as a few infants ${ }^{13}$ with this syndrome.

This study was supported in part by the University of Illinois Foundation Goodenberger Medical Research Grant.

\section{References}

1 Macartney FJ, Miller GAH. Congenital absence of the pulmonary valve. $B r$ Heart $\mathcal{F} 1970$; 32: 483-90.

2 Lakier JB, Stanger P, Heymann MA, Hoffman JIE, Rudolf AM. Tetralogy of Fallot with absent pulmonary valve. Natural history and hemodynamic considerations. Circulation 1974; 50: 167-75.

3 Emmanouilides GC, Thanopoulos B, Siassi B, Fishbein M. "Agenesis" of ductus arteriosus associated with the syndrome of tetralogy of Fallot and absent pulmonary valve. Am f Cardiol 1976; 37: 403-9.

4 Chevers N. A collection of facts illustrative of the morbid conditions of the pulmonary valve, as bearing upon the treatment of cardiac and pulmonary diseases. London Medical Gazette 1846; 38: 828-35.

5 Ito T, Engle MA, Holswade GR. Congenital insufficiency of the pulmonic valve. A rare cause of neonatal heart failure. Pediatrics 1961; 28: 712-8.

6 Smith RD, DuShane JW, Edwards JE. Congenital insufficiency of the pulmonary valve including a case of fetal cardiac failure. Circulation 1959; 20: 554-60.

7 Chiemmongkoltip P, Replogle RL, Arcilla RA. Congenital absence of the pulmonary valve with atrial septal defect surgically corrected with aortic homograft. Chest 1972; 62: 100-3.

8 Chiders RW, McCrea PC. Absence of the pulmonary valve. Circulation 1964; 29: 598-603.

9 Roach MR. Changes in arterial distensibility as a cause of poststenotic dilatation. Am $\mathcal{f}$ Cardiol 1963; 12: 802-15.

10 Campeau L, Gilbert G, Aerichide N. Absence of the pulmonary valve. Report of two cases associated with other congenital lesions. Am f Cardiol 1961; 8: 113-24.

11 Saldana M, Arias-Stella J. Studies on structure of pulmonary trunk. Normal changes in elastic configuration of human pulmonary trunk at different ages. Circulation 1963; 27: 1086-93.

12 Ilbawi MN, Idriss FS, Muster AJ, Wessel HU, Paul MH, DeLeon SY. Tetralogy of Fallot with absent pulmonary valve. Should valve insertion be part of the intracardiac repair? I Thorac Cardiovasc Surg 1981; 81: 906-15.

13 Dunnigan A, Oldham HN, Benson DW. Absent pulmonary valve syndrome in infancy: surgery reconsidered. Am F Cardiol 1981; 48: 117-22. 